\title{
低温胁迫下聚糠萗合剂对玉米幼苗光合作用和抗氧化酶活性的影响
}

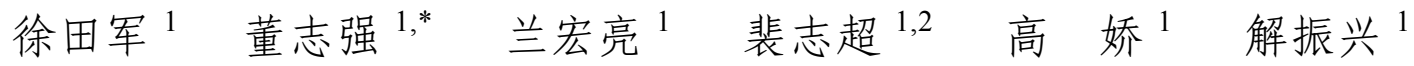

${ }^{1}$ 中国农业科学院作物科学研究所 / 农业部作物生理生态与栽培重点开放实验室, 北京 $100081 ;{ }^{2}$ 北京市农业技术推广站, 北京 100029

摘 要: 采用盆栽试验, 以郑单 958 和丰单 3 号为材料, 研究了低温胁迫对玉米幼苗光合作用、叶绿素、叶绿素苂光 参数和抗氧化酶活性的影响, 以及聚糠萗合剂(PKN)的调控效果。结果表明, 低温胁迫下, 玉米幼苗的光合作用和光 系统 II 光化学最大效率受到抑制; 超氧化物歧化酶(SOD)、过氧化物酶(POD)和过氧化氢酶(CAT)活性降低; 过氧化 氢、超氧阴离子的产生速率及丙二醛 $(\mathrm{MDA})$ 含量显著升高。PKN 处理提高了低温胁迫下玉米幼苗净光合速率 $\left(P_{\mathrm{n}}\right)$ 、 气孔导度 $\left(G_{\mathrm{s}}\right)$ 、光系统 II 光化学的最大效率 $\left(F_{\mathrm{v}} / F_{\mathrm{m}}\right)$ 、叶绿素含量 $(\mathrm{Chl} \mathrm{a}+\mathrm{Chl} \mathrm{b})$ 。低温处理 $7 \mathrm{~d}$, 郑单 958 处理 $($ ZDTR) 和丰单3号处理(FDTR)的 $P_{\mathrm{n}} 、 G_{\mathrm{s}} 、 F_{\mathrm{v}} / F_{\mathrm{m}} 、 \mathrm{Chl} \mathrm{a}+\mathrm{Chl} \mathrm{b}$ 分别比各自的对照提高了 $88.95 \%$ 和 $61.11 \% 、 593.33 \%$ 和 $1741.67 \%$ 、 $111.50 \%$ 和 $145.16 \%$ 、36.61\%和 54.03\%; PKN 处理延缓了 SOD、POD、CAT 活性的降低, 低温胁迫 $7 \mathrm{~d}$, PKN 处理使 郑单 958 和丰单 3 号的 SOD、POD、CAT 活性分别比对照高了 $292.59 \%$ 和 $632.98 \%$ 、295.07\%和 $360.54 \%$ 、254.55\% 和 $265.45 \%$; 同时降低了过氧化氢、超氧阴离子的产生速率及 MDA 的含量。表明 PKN 处理有利于提高玉米幼苗的 抗冷性。

关键词：冷害胁迫；抗氧化酶；光合作用；玉米幼苗；化学调控

\section{Effects of PASP-KT-NAA on Photosynthesis and Antioxidant Enzyme Activities of Maize Seedlings under Low Temperature Stress}

\author{
XU Tian-Jun ${ }^{1}$, DONG Zhi-Qiang ${ }^{1, *}$, LAN Hong-Liang ${ }^{1}$, PEI Zhi-Chao ${ }^{1,2}$, GAO Jiao ${ }^{1}$, and XIE Zhen-Xing ${ }^{1}$ \\ ${ }^{1}$ Institute of Crop Sciences, Chinese Academy of Agricultural Sciences / Key Laboratory of Crop Eco-physiology and Cultivation, Beijing 100081, \\ China; ${ }^{2}$ Beijing Agricultural Technology Extension Station, Beijing 100029, China
}

\begin{abstract}
A pot experiment of maize seedlings was conducted to investigate the effects of low temperature stress and the chemical regulator of PASP-KT-NAA (PKN) on photosynthetic, physiological parameters, chlorophyll contents, and various antioxidant enzymes activities. The results showed that, in maize seedlings under low temperature stress, the photosynthesis ability and SOD, POD, CAT activities reduced; the formation speed of hydrogen peroxide and superoxide anion, as well as MDA contents increased. PKN pretreatment increased $P_{\mathrm{n}}, G_{\mathrm{s}}, F_{\mathrm{v}} / F_{\mathrm{m}}$, and chlorophyll contents. Under low temperature stress for seven days, $P_{\mathrm{n}}, G_{\mathrm{s}}$, $F_{\mathrm{v}} / F_{\mathrm{m}}$, chlorophyll contents of Zhengdan 958 treatment (ZDTR) and Fengdan 3 treatment (FDTR) were higher than those of CK, which was increased by $88.95 \%$ and $61.11 \%, 593.33 \%$ and $1741.67 \%, 111.50 \%$ and $145.16 \%, 36.61 \%$ and $54.03 \%$. While the formation speed of hydrogen peroxide and superoxide anion reduced, MDA contents decreased too. Simultaneously, SOD, POD, CAT activities were increased by $292.59 \%$ and $632.98 \%, 295.07 \%$ and $360.54 \%, 254.55 \%$ and $265.45 \%$. In conclusion, PKN pretreatment can improve the cold resistance of maize seedlings
\end{abstract}

Keywords: Low temperature stress; Antioxidant enzyme; Photosynthesis; Maize seedlings; PKN regulation

低温冷害是中国东北春玉米产区常见的气象灾 害, 是玉米高产稳产的主要限制因素 ${ }^{[1-2]}$ 。一般每隔 3 5 年就有一次严重的低温冷害, 如 1954、1957、 1969、1972、1976 等年份，每年因低温冷害造成的 春玉米减产幅度均在 15\%以上; 1995 和 1997 年 9 月
中旬的局域性早霜，单产减少 $10 \% \sim 15 \%{ }^{[3]}$ 。现代生 物技术研究结果表明, 植物干重的 $90 \%$ 来自光合作 用, 而光合作用对低温最敏感 ${ }^{[4]}$ 。史占忠等 ${ }^{[5]}$ 研究发 现, 低温胁迫明显减弱玉米功能叶片的光合作用强 度, 减弱程度随低温程度和持续时间的增加而增

\footnotetext{
本研究由国家自然科学基金项目(30971726)和国家科技支撑计划项目(2006BAD02A13-4)资助。

* 通讯作者(Corresponding author): 董志强, E-mail: dongzhiqiang@126.com, Tel: 010-82106043

第一作者联系方式: E-mail: xtjxtjbb@163.com

Received(收稿日期): 2011-03-31; Accepted(接受日期): 2011-07-25; Published online(网络出版日期): 2011-11-07.

URL: http://www.cnki.net/kcms/detail/11.1809.S.20111107.1046.005.html
} 
大。低温胁迫导致玉米植株对 $\mathrm{O}_{2}$ 的利用能力降低, 几余的 $\mathrm{O}_{2}$ 在代谢过程中被转化成活性氧(AOS), 危 害植物的正常生理代谢过程; 而植株体内的 SOD、 POD、CAT 等抗氧化酶系统是清除活性氧, 保障生 理代谢正常进行的重要酶系统。Fryer 等 ${ }^{[6]}$ 研究表明 低温胁迫下玉米叶片中 SOD、CAT、POD 等活性降 低而 MDA 的含量明显升高。采取合理的措施可以 在一定范围内缓解冷害对玉米的影响, 如应用乙烯

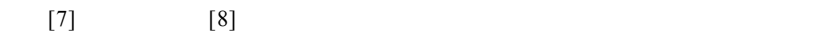
透调节物以及钾、磷等矿质元素 ${ }^{[9-11]}$ 均可以在一定程 度上缓解冷害的胁迫, 但在使用及效果上都存在局 限性, 在生产中难以大面积推广。

聚糠萗合剂(PKN)是针对东北春玉米产区的低 温冷害特点而研制的抗冷调节剂, 目前在东北春玉 米区已经大面积示范应用且对 PKN 的主成分在植物 抗逆性中的作用已有大量的报道。刘芸等 ${ }^{[12]}$ 以栝楼 幼苗为材料研究表明外施 $\alpha-N A A$ 能提高叶片叶绿 素及类胡夢卜素的含量,提高保护酶 SOD、CAT、 POD、ASP 的活性, 增强幼苗的抗逆性。Leshem 等 ${ }^{[13]}$ 以树木为材研究表明, 细胞分裂素(KT)可直接或间 接地清除自由基, 减少脂质过氧化作用, 提高 SOD 等膜保护酶的活性, 改变膜脂过氧化产物、膜脂肪酸 组成的比例, 保护细胞膜, 增加抗逆性。冷一欣等 ${ }^{[14]}$ 叶面喷施聚天门冬氨酸(PASP)增加了玉米的生物学 产量。PKN 是 PASP、KT、NAA 的复配剂, 其抗冷 机制有待进一步明确。在明确春玉米苗期低温冷害 胁迫机制的前提下, 研究 PKN 对玉米光合作用相关 生理指标及抗氧化酶系统的影响, 对进一步明确 PKN 的抗冷生理机制、完善 PKN 的应用技术、保障 东北地区春玉米高产稳产具有重要意义。

\section{1 材料与方法}

\section{1 试验设计}

以不同基因型的品种郑单958 (适宜于有效积温 $\geqslant 1954.7^{\circ} \mathrm{C}$ 区域种植)和丰单 3 号(适宜于有效积温 $\geqslant 1140^{\circ} \mathrm{C}$ 区域种植) 为材料, 选择良好的种子, 于 $0.02 \%(W / V)$ 的氯化永溶液中浸泡 $5 \mathrm{~min}$, 然后用蒸 馏水反复冲洗，最后将种子置 $37^{\circ} \mathrm{C}$ 恒温箱内催芽。 将萌发后的种子播在 $10 \mathrm{~cm} \times 10 \mathrm{~cm} \times 6 \mathrm{~cm}$ 的塑料盒 中, 人工气候室 $\left(\mathrm{GXZ}\right.$ 智能型人工气候室) $25 \sim 27^{\circ} \mathrm{C}$ 下培养幼苗至三叶期。选取两品种长势一致的幼苗 各 160 株, 共 320 株。将每品种幼苗分为两组, 每组 80 株。设置化控处理, 将每品种中一组叶面喷施 200 $\mathrm{mg} \mathrm{L}^{-1}$ 聚糠萗合剂(PASP-KT-NAA, 以下简称 PKN),
另一组为清水对照。化控处理 $1 \mathrm{~d}$ 后, 将两品种 320 株幼苗置低温培养室内 $\left(5^{\circ} \mathrm{C}\right.$, 光强 $400 \mu \mathrm{mol} \mathrm{m} \mathrm{m}^{-2} \mathrm{~s}^{-1}$, 光照 $12 \mathrm{~h} \mathrm{~d}^{-1}$ ), 连续胁迫 $7 \mathrm{~d}$ 。期间培养室内 $\mathrm{CO}_{2}$ 浓 度、光照时间和光照强度与人工气候室培养环境一 致。低温胁迫 0 7 d 内, 每天取样(1 3 展开叶)一次, 共 8 次; 各处理每次取 8 株, 样品经液氮处理后, $-20^{\circ} \mathrm{C}$ 下保存, 待测相关生理指标。于低温胁迫的第 $0 、 1 、 3 、 5 、 7$ 天测定第 3 片展开叶的净光合速率、 胞间 $\mathrm{CO}_{2}$ 浓度、气孔导度和叶绿素荧光参数 $\left(F_{\mathrm{v}} / F_{\mathrm{m}}\right)$, 3 次重复。

聚糠萗合剂(PKN), 属于植物生长促进剂类, 可 显著提高作物的抗逆性。由中国农业科学院作物科 学研究所栽培生理系提供。

\section{2 测定项目与方法}

1.2.1 叶绿素含量测定 参照 Arnon $^{[15]}$ 的方法。 用直径为 $0.43 \mathrm{~cm}$ 的打孔器, 打取叶圆片, 用 $10 \mathrm{~mL}$ $95 \%$ 的乙醇避光提取 $48 \mathrm{~h}$ 后, 用日本岛津公司产 UV-4802 型双通道紫外-可见分光光度计测定 $649 \mathrm{~nm}$ 和 $665 \mathrm{~nm}$ 的吸光值。

1.2.2 过氧化氢 $\left(\mathrm{H}_{2} \mathrm{O}_{2}\right)$ 含量测定 参照林植芳等 ${ }^{[16]}$ 的方法。按王爱国等 ${ }^{[17]}$ 的方法测定超氧阴离子 $\left(\mathrm{O}_{2}^{-}\right)$ 产生速率。

1.2.3 超氧化物歧化酶(SOD)活性测定按照王 爱国 ${ }^{[17]}$ 的方法。吸取 $20 \mu \mathrm{L}$ 酶液, 加入 $3 \mathrm{~mL}$ SOD 反 应液 $\left(\mathrm{pH} 7.8\right.$ 的磷酸缓冲液 $1.5 \mathrm{~mL}, 130 \mathrm{mmol} \mathrm{L}^{-1} \mathrm{Met}$ $0.3 \mathrm{~mL}, 750 \mu \mathrm{mol} \mathrm{L}{ }^{-1}$ NBT $0.3 \mu L, 100 \mu \mathrm{mol} \mathrm{L}^{-1}$ EDTA-Na $\mathrm{Na}_{2} 0.3 \mathrm{~mL}, 20 \mu \mathrm{mol} \mathrm{L}{ }^{-1} \mathrm{FD} 0.3 \mathrm{~mL}$, 蒸馏水 $0.3 \mathrm{~mL}), 72 \mu \mathrm{mol} \mathrm{m}^{-2} \mathrm{~s}^{-1}$ 照光 $30 \mathrm{~min}$, 对照 $(\mathrm{CK})$ 与酶 液置相同条件下光照, 空白置暗处, 用于调零, $560 \mathrm{~nm}$ 比色。

1.2.4 过氧化氢酶 (CAT) 活性测定按照 Chance ${ }^{[18]}$ 的方法。0.1 mL 酶液加 $2.5 \mathrm{~mL}$ CAT 反应 液 $\left(0.1 \mathrm{~mol} \mathrm{~L}^{-1} \mathrm{H}_{2} \mathrm{O}_{2}\right.$ 溶液 $0.5 \mathrm{~mL}, 0.1 \mathrm{~mol} \mathrm{~L}^{-1} \mathrm{pH} 7.0$ 的磷酸缓冲液 $2.5 \mathrm{~mL}$ ), $240 \mathrm{~nm}$ 下比色, 每隔 $30 \mathrm{~s}$ 读 取吸光度的下降值。

1.2.5 过氧化物酶 (POD) 活性测定参照李忠 光 ${ }^{[19]}$ 的方法。用愈创木酚法 $20 \mu \mathrm{L}$ 酶液加入 $30 \mathrm{~mL}$ POD 反应液(愈创木酚 $1.4 \mu \mathrm{L}, 30 \% \mathrm{H}_{2} \mathrm{O}_{2} 0.85 \mu \mathrm{L}$ 和 $0.1 \mathrm{~mol} \mathrm{~L}^{-1} \mathrm{pH} 6.0$ 的磷酸缓冲液), 在 $470 \mathrm{~nm}$ 下每隔 $30 \mathrm{~s}$ 读取吸光值增加数。

1.2.6 丙二醛(MDA)含量测定参照林植芳 ${ }^{[20]}$ 的 方法。 $1 \mathrm{~mL}$ 酶液加 $0.6 \% \mathrm{TBA} 2 \mathrm{~mL}$, 沸水浴 $15 \mathrm{~min}$, 迅速冷却后离心, 取上清液, 分别在 $600 \mathrm{~nm} 、 532 \mathrm{~nm}$ 和 $450 \mathrm{~nm} 3$ 个波长下比色。 
1.2.7 光合生理参数的测定 采用 Li-6400 (美国) 便携式光合作用测定仪测定玉米幼苗完全展开的第 3 叶的净光合速率 $\left(P_{\mathrm{n}}\right)$ 、胞间 $\mathrm{CO}_{2}$ 浓度 $\left(C_{\mathrm{i}}\right)$ 、气孔导 度 $\left(G_{\mathrm{s}}\right)$ 。测定过程中光强约为 $900 \mu \mathrm{mol} \mathrm{m} \mathrm{m}^{-2} \mathrm{~s}^{-1}$, 大 气温度 $(20 \pm 1)^{\circ} \mathrm{C}$, 大气 $\mathrm{CO}_{2}$ 浓度变化范围为 $(400 \pm$ 15) $\mu \mathrm{mol} \mathrm{mol}^{-1}$ 。

1.2.8 叶绿素荧光的测定采用 FMS2 脉冲调制 式苂光仪(Hansatech, UK), 主要测定光适应下的最 大苂光 $\left(F_{\mathrm{m}}{ }^{\prime}\right)$ 、最小苂光 $\left(F_{\mathrm{o}}{ }^{\prime}\right)$ 、稳态苂光 $\left(F_{\mathrm{s}}\right)$ 等苂光参 数; 暗适应 $30 \mathrm{~min}$ 后测定初始苂光 $\left(F_{\mathrm{o}}\right)$ 、最大苂光 $\left(F_{\mathrm{m}}\right)$; 参照 Demming-Adams 等 ${ }^{[21]}$ 方法计算 PSII 最大 光化学效率 $\left(F_{\mathrm{v}} / F_{\mathrm{m}}\right)$ 。每处理选取 6 株测定, 测定 4 次, 取其平均值。

\section{3 数据处理}

采用 DPS6.5 软件进行数据方差分析, 其中采 用 $\operatorname{LSD}$ 检验 $(P<0.05)$ 处理平均数间差异显著性。用 Sigma plot 10.0 进行数据计算和作图。

\section{2 结果与分析}

2.1 低温胁迫下聚糠萗合剂对玉米光合性能指 标的影响

由表 1 可以看出, 随着低温胁迫时间的延长, 两 品种幼苗的净光合速率均呈明显下降的趋势。表现 为低温胁迫 $1 \mathrm{~d}$ 时, 郑单 958 (ZDCK) 和丰单 3 号 (FDCK) 对照植株的净光合速率下降较缓, 降幅分别 为 $14.52 \%$ 和 $13.82 \%$; 之后急剧下降, 低温胁迫 $3 \mathrm{~d}$ 、 $7 \mathrm{~d}$, ZDCK 和 FDCK 净光合速率与低温处理前相比 降幅分别为 $48.26 \% 、 76.55 \%$ 和 $52.60 \% 、 83.95 \%$ 。 $\mathrm{PKN}$ 处理显著提高了两品种的净光合速率。其中与 对照相比, 郑单 958 增幅为 $10.55 \%$ $90.53 \%$, 丰单 3 号增幅为 $8.93 \% \sim 67.07 \%$ 。

随低温胁迫时间的延长, 两品种幼苗的气孔导 度 $\left(G_{\mathrm{s}}\right)$ 均呈下降的趋势。其中, 低温胁迫 $1 \mathrm{~d}$, 两品种 玉米幼苗的气孔导度下降较缓, ZDCK 和 FDCK 的 $G_{\mathrm{s}}$ 降幅分别为 $16.91 \%$ 和 $27.40 \%$; 随低温胁迫时间 的延长, 气孔导度急剧下降, 与低温处理 $5 \mathrm{~d}$ 相比, 低温胁迫 $7 \mathrm{~d}$, ZDCK 和 FDCK 的 $G_{\mathrm{s}}$ 降幅分别为 $89.58 \%$ 和 $87.75 \%$ 。PKN 处理显著减缓了玉米叶片气 孔导度的下降速率。低温胁迫 $0 \sim 7 \mathrm{~d}$, 郑单 958 比对 照增加了 $10.33 \%$ 593.33\%, 丰单 3 号增加了 $14.09 \%$ $\sim 1741.67 \%$ 。

随着低温胁迫时间的延长, 两品种的胞间 $\mathrm{CO}_{2}$ 浓度 $\left(C_{\mathrm{i}}\right)$ 呈先下降后上升的趋势, 最低值出现在低 温胁迫 $1 \mathrm{~d}$, 与胁迫前比较, ZDCK 和 FDCK 的 $C_{\mathrm{i}}$ 降
幅分别为 $27.29 \%$ 和 $24.30 \%$; 低温胁迫 3 7 d, ZDCK 和 FDCK 的 $C_{\mathrm{i}}$ 依次上升, 增幅相当于各自最低值的 $79.92 \% \sim 81.93 \%$ 和 $78.82 \% \sim 81.18 \%$; PKN 处理显著 降低了幼苗胞间 $\mathrm{CO}_{2}$ 浓度, 其中, 郑单 958 与对照 相比降低了 $7.80 \%$ 23.15\%, 丰单 3 号降低了 $5.93 \%$ $29.83 \%$ 。

2.2 低温胁迫下聚糠萗合剂对玉米幼苗干物重 的影响

如图 1 所示, 随低温胁迫时间的延长, ZDCK 的 干物重在低温胁迫 $0 \sim 3 \mathrm{~d}$ 内呈直线上升趋势, $3 \sim 7 \mathrm{~d}$ 后上升幅度减小; FDCK 的干物重在 $0 \sim 2 \mathrm{~d}$ 迅速增加, 之后增加的幅度减小。PKN 处理显著增加了两品种 的干物重。其中, 低温胁迫 2 7 d, ZDTR 的干物重比 各自的对照增加了 $1.12 \%$ 9.48\%, 而 FDTR 增加了 $8.52 \% \sim 15.31 \%$ 。

2.3 低温胁迫下聚糠萗合剂对玉米叶片叶绿素 含量的影响

如图 2 所示, 不同品种间的叶绿素含量差异极 显著, 郑单 958 高于丰单 3 号。ZDCK 在低温胁迫 0 3 $\mathrm{d}$ 内叶绿素含量呈直线下降趋势, 3 7 d 后下降幅度 减小; 随低温胁迫时间的延长, FDCK 的叶绿素含量 呈直线下降趋势。PKN 处理显著降低了两品种的叶 绿素含量下降速率, 提高了两品种的叶绿素含量。 其中, 低温胁迫 2 7 d, ZDTR 的叶绿素含量比各自 的对照增加了 $8.37 \%$ 36.61\%, FDTR 增加了 4.71\% $54.03 \%$ 。

2.4 低温胁迫下聚糠萗合剂对玉米叶片 $F_{\mathrm{v}} / F_{\mathrm{m}}$ 的 影响

PSII 光化学效率 $\left(F_{\mathrm{v}} / F_{\mathrm{m}}\right)$ 是反映光抑制和逆境胁 迫程度的指标。由图 3 可以看出, 随低温胁迫时间 的延长, 两品种对照植株的 $F_{\mathrm{v}} / F_{\mathrm{m}}$ 呈下降趋势。其中, ZDCK 表现为, 低温胁迫 0 2 d, $F_{\mathrm{v}} / F_{\mathrm{m}}$ 急剧下降; 低 温胁迫 3 7 d, $F_{\mathrm{v}} / F_{\mathrm{m}}$ 下降速率减缓; 而 FDCK 则表现 为, 低温胁迫 $0 \sim 7 \mathrm{~d}, F_{\mathrm{v}} / F_{\mathrm{m}}$ 一直呈现直线下降趋势。 PKN 处理降低了两品种叶片的 $F_{\mathrm{v}} / F_{\mathrm{m}}$ 下降幅度, 提 高了两品种的 $F_{\mathrm{v}} / F_{\mathrm{m}}$ 值。低温胁迫 $0 \sim 7 \mathrm{~d}$, 郑单 958 的 $F_{\mathrm{v}} / F_{\mathrm{m}}$ 与其对照相比增幅为 $39.19 \% \sim 111.50 \%$, 丰 单 3 号增幅为 $32.72 \% \sim 145.16 \%$ 。

2.5 低温胁迫下聚糠萗合剂对玉米叶片膜脂过 氧化和保护酶活性的影响

2.5.1 低温胁迫下聚糠䒬合剂对玉米叶片过氧化氢 和超氧阴离子含量的影响 由图 4 可知, 两品种 玉米幼苗的 $\mathrm{H}_{2} \mathrm{O}_{2}$ 含量和超氧阴离子产生速率，随低 温胁迫时间的延长均呈上升趋势, 且丰单 3 号明显高 
表 1 低温胁迫下聚糠萗合剂对玉米叶片光合性能指标的影响

Table 1 Effect of PKN on photosynthesis parameter of the maize seedlings under cold stress

\begin{tabular}{|c|c|c|c|c|c|c|}
\hline \multirow{2}{*}{$\begin{array}{c}\text { 参数 } \\
\text { Parameter }\end{array}$} & \multirow{2}{*}{$\begin{array}{c}\text { 处理 } \\
\text { Treatment }\end{array}$} & \multicolumn{5}{|c|}{ 低温处理时间 Time of chill treatment } \\
\hline & & $0 \mathrm{~d}$ & $1 \mathrm{~d}$ & $3 \mathrm{~d}$ & $5 \mathrm{~d}$ & $7 \mathrm{~d}$ \\
\hline 净光合速率 & ZDCK & $8.06 \pm 0.49 b$ & $6.89 \pm 0.53 \mathrm{~b}$ & $4.17 \pm 0.39 \mathrm{~b}$ & $2.81 \pm 0.28 \mathrm{~b}$ & $1.89 \pm 0.31 \mathrm{~b}$ \\
\hline \multirow{3}{*}{$\begin{array}{l}\text { Photosynthetic rate } \\
\left(\mathrm{CO}_{2} \mu \mathrm{mol} \mathrm{m} \mathrm{m}^{-2} \mathrm{~s}^{-1}\right)\end{array}$} & ZDTR & $8.91 \pm 0.50 \mathrm{a}$ & $7.92 \pm 0.45 \mathrm{a}$ & $5.75 \pm 0.34 \mathrm{a}$ & $4.38 \pm 0.29 \mathrm{a}$ & $3.59 \pm 0.37 \mathrm{a}$ \\
\hline & FDCK & $6.73 \pm 0.45 c$ & $5.80 \pm 0.41 \mathrm{c}$ & $3.19 \pm 0.32 \mathrm{c}$ & $1.54 \pm 0.45 \mathrm{~d}$ & $1.08 \pm 0.23 \mathrm{~d}$ \\
\hline & FDTR & $7.34 \pm 0.36 \mathrm{c}$ & $6.37 \pm 0.43 \mathrm{c}$ & $4.05 \pm 0.29 \mathrm{~b}$ & $2.57 \pm 0.44 \mathrm{c}$ & $1.74 \pm 0.25 \mathrm{c}$ \\
\hline \multirow{4}{*}{$\begin{array}{c}\text { 气孔导度 } \\
\text { Stomatal conductance } \\
\left(\mathrm{mmol} \mathrm{m}^{-2} \mathrm{~s}^{-1}\right)\end{array}$} & ZDCK & $36.78 \pm 4.56 \mathrm{~b}$ & $30.56 \pm 3.43 \mathrm{~b}$ & $13.67 \pm 2.87 \mathrm{c}$ & $4.32 \pm 0.81 \mathrm{c}$ & $0.45 \pm 0.03 \mathrm{c}$ \\
\hline & ZDTR & $40.58 \pm 5.56 \mathrm{a}$ & $34.45 \pm 4.43 \mathrm{a}$ & $18.67 \pm 3.87 \mathrm{a}$ & $11.56 \pm 2.10 \mathrm{a}$ & $3.12 \pm 1.32 \mathrm{a}$ \\
\hline & FDCK & $33.21 \pm 3.98 \mathrm{c}$ & $24.11 \pm 3.01 \mathrm{c}$ & $9.32 \pm 1.12 \mathrm{~d}$ & $0.98 \pm 0.06 \mathrm{~d}$ & $0.12 \pm 0.04 \mathrm{c}$ \\
\hline & FDTR & $37.89 \pm 4.01 \mathrm{~b}$ & $30.76 \pm 3.21 \mathrm{~b}$ & $18.75 \pm 2.21 \mathrm{~b}$ & $8.78 \pm 1.11 \mathrm{~b}$ & $2.21 \pm 0.87 \mathrm{~b}$ \\
\hline \multirow{4}{*}{$\begin{array}{c}\text { 胞间 } \mathrm{CO}_{2} \text { 浓度 } \\
\text { Intercellular } \mathrm{CO}_{2} \text { con- } \\
\text { centration }\left(\mu \mathrm{mol} \mathrm{mol}^{-1}\right)\end{array}$} & ZDCK & $310.21 \pm 20.12 b$ & $225.56 \pm 16.22 b$ & $521.21 \pm 25.45 b$ & $992.34 \pm 28.54 b$ & $1124.32 \pm 31.32 b$ \\
\hline & ZDTR & $286.12 \pm 18.91 \mathrm{~d}$ & $186.45 \pm 13.71 \mathrm{~d}$ & $400.56 \pm 23.78 \mathrm{~d}$ & $789.12 \pm 26.98 \mathrm{~d}$ & $899.34 \pm 30.12 d$ \\
\hline & FDCK & $320.34 \pm 25.52 \mathrm{a}$ & $241.23 \pm 15.83 \mathrm{a}$ & $568.98 \pm 24.32 \mathrm{a}$ & $1129.43 \pm 27.79 \mathrm{a}$ & $1334.56 \pm 34.54 \mathrm{a}$ \\
\hline & FDTR & $301.32 \pm 21.73 \mathrm{c}$ & $198.98 \pm 13.23 \mathrm{c}$ & $430.56 \pm 20.11 \mathrm{c}$ & $821.43 \pm 23.54 \mathrm{c}$ & $936.45 \pm 28.91 \mathrm{c}$ \\
\hline
\end{tabular}

ZDTR: 郑单 958 处理; ZDCK: 郑单 958 对照; FDTR: 丰单 3 号处理; FDCK: 丰单 3 号对照。不同字母表示差异在 0.05 水平显著。

ZDTR: Zhengdan 958 treatment; ZDCK: Zhengdan 958 CK; FDTR: Fengdan 3 treatment; FDCK: Fengdan 3 CK. Treatments with significant differences $(P<0.05)$ are marked with different letters.

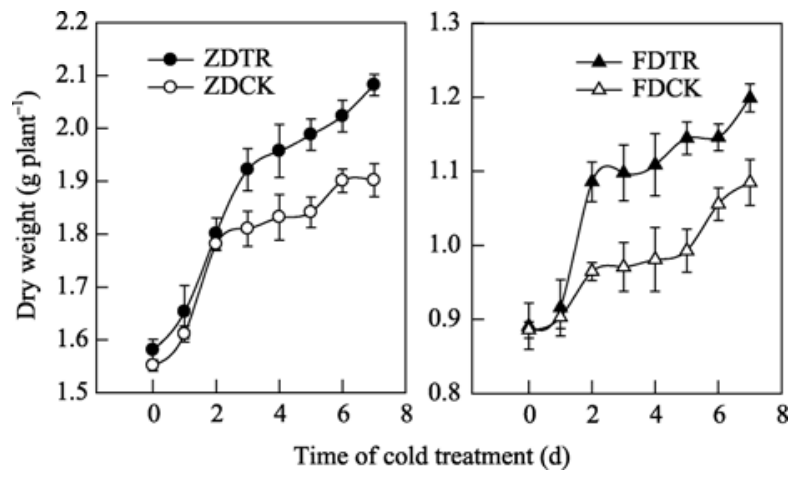

图 1 低温胁迫下聚糠萗合剂对玉米幼苗干物重的影响

Fig. 1 Effect of PKN on dry weight of the maize seedlings under cold stress

ZDTR: 郑单 958 处理; ZDCK: 郑单 958 对照; FDTR: 丰单 3 号 处理; FDCK: 丰单 3 号对照。

ZDTR: Zhengdan 958 treatment; ZDCK: Zhengdan 958 CK; FDTR: Fengdan 3 treatment; FDCK: Fengdan 3 CK.

于郑单 958。低温胁迫 $7 \mathrm{~d}, \mathrm{ZDCK}$ 和 FDCK 的 $\mathrm{H}_{2} \mathrm{O}_{2}$ 含量与各自低温胁迫前相比分别升高了 $61.21 \%$ 和 $60.43 \%$ ，超氧阴离子产生速率分别升高了 $65.62 \%$ 和 $63.01 \%$ 。

PKN 处理的植株 $\mathrm{H}_{2} \mathrm{O}_{2}$ 含量和超氧阴离子的产 生速率较对照均显著降低, 并且, 随低温胁迫时间 的延长, 与对照之间的差异均逐渐变大。低温胁迫 0 7 d, ZDTR 的 $\mathrm{H}_{2} \mathrm{O}_{2}$ 含量比 ZDCK 降低了 $15.96 \%$ $29.17 \%$, FDTR 比 FDCK 降低了 20.72\% 32.01\%; ZDTR 的超氧阴离子的产生速率与其对照相比降低 了 9.70\% 19.69\%, FDTR 降低了 11.40\% 20.70\%。

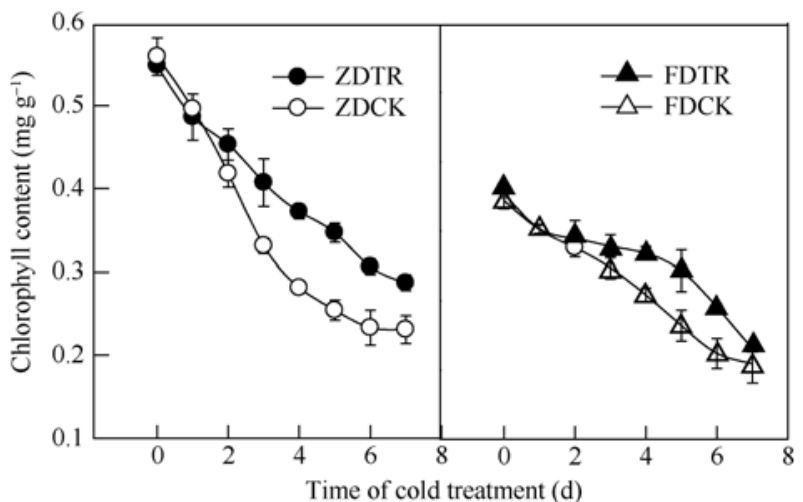

图 2 低温胁迫下聚糠萗合剂对玉米叶片中叶绿素含量的影响 Fig. 2 Effect of PKN on chlorophyll content of maize seedlings under cold stress

ZDTR: 郑单 958 处理; ZDCK：郑单 958 对照; FDTR: 丰单 3 号 处理; FDCK: 丰单 3 号对照。

ZDTR: Zhengdan 958 treatment; ZDCK: Zhengdan 958 CK; FDTR: Fengdan 3 treatment; FDCK: Fengdan 3 CK.

2.5.2 低温胁迫下聚糠菜合剂对玉米幼苗膜脂过氧 化作用的影响 MDA 为膜脂过氧化产物, 标志 着膜脂的过氧化程度。从图 5 可看出, 随低温胁迫 时间的延长, 两品种玉米叶片中 MDA 含量呈增加 趋势。低温胁迫 0 2 d 时, ZDCK 和 FDCK 的 MDA 含量缓慢上升; 低温胁迫 3 7 d, 急剧上升。低温胁 迫 $7 \mathrm{~d}$ 的 ZDCK 和 FDCK 的 MDA 含量与低温胁迫 前相比分别增加了 $83.03 \%$ 和 $80.01 \%$ 。PKN 处理两 品种叶片的 MDA 含量显著降低, 低温胁迫 3 7 d 时, ZDTR 的 MDA 含量比对照降低了 $22.18 \%$ 25.33\%, 


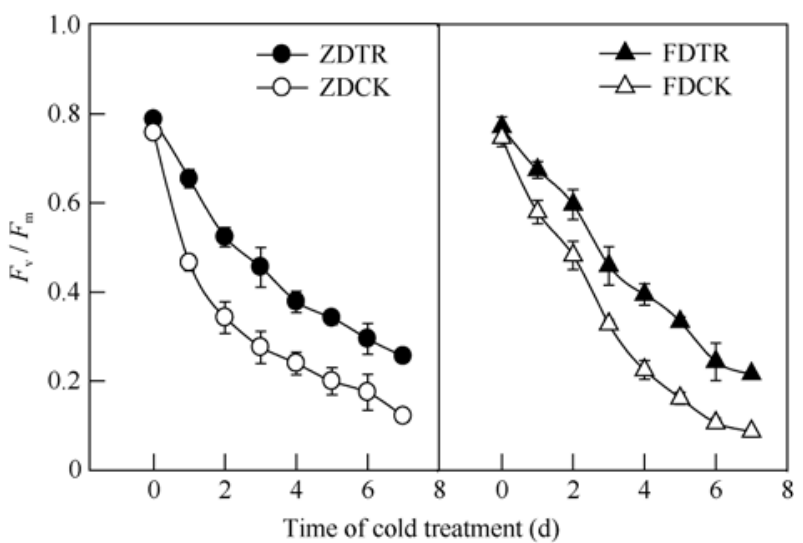

图 3 低温胁迫下聚糠荎合剂对玉米叶片中光系统 II 光化学最 大效率的影响

Fig. 3 Effect of $P K N$ on $F_{v} / F_{m}$ of maize seedlings under cold stress ZDTR：郑单 958 处理; ZDCK：郑单 958 对照; FDTR：丰单 3 号 处理; FDCK: 丰单 3 号对照。

ZDTR: Zhengdan 958 treatment; ZDCK: Zhengdan 958 CK; FDTR: Fengdan 3 treatment; FDCK: Fengdan 3 CK.

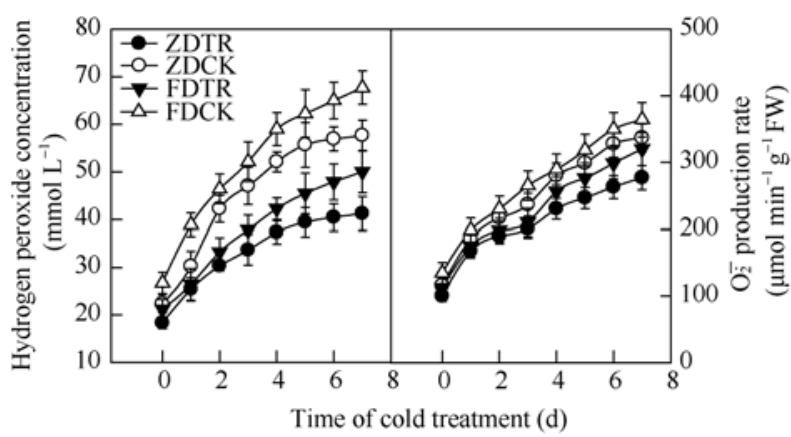

图 4 低温胁迫下聚糠萗合剂对玉米叶片 $\mathrm{H}_{2} \mathrm{O}_{2}$ 含量和 $\mathrm{O}_{2}^{-}$产生 速率的影响

Fig. 4 Effect of PKN on hydrogen peroxide concentration and

$\mathrm{O}_{2}^{-}$production rate of the maize seedlings under cold stress ZDTR: 郑单 958 处理; ZDCK：郑单 958 对照; FDTR: 丰单 3 号 处理; FDCK: 丰单 3 号对照。

ZDTR: Zhengdan 958 treatment; ZDCK: Zhengdan 958 CK; FDTR: Fengdan 3 treatment; FDCK: Fengdan 3 CK.

FDTR 比对照降低了 $16.48 \%$ 25.37\%。

2.5 .3 低温胁迫对玉米幼苗抗氧化酶活性的影响与 化学调控 SOD 是生物防御活性氧伤害的重要保 护酶之一。从图 6 可看出, 随低温胁迫的延长, 2 个 品种叶片中 SOD 活性呈单峰曲线变化, 峰值出现在 低温胁迫 $2 \mathrm{~d}$ 。低温胁迫 0 2 d, 2 个品种对照植株的 SOD 活性逐渐升高, ZDCK 和 FDCK 的 SOD 活性比 低温处理前分别升高了 $37.98 \%$ 和 $33.19 \%$ 。低温胁迫 2 7 d, SOD 活性急剧下降。与低温处理 $2 \mathrm{~d}$ 相比, 低 温胁迫 $7 \mathrm{~d}$, ZDCK 和 FDCK 的 SOD 活性分别降低了 $87.57 \%$ 和 $93.47 \%$ 。PNK 处理玉米叶片 SOD 活性显 著高于对照, 低温胁迫 0 7 d, ZDTR 和 FDTR与各自 对照相比增加幅度分别为 $11.29 \%$ 292.59\%和 4.57\% $632.98 \%$ 。

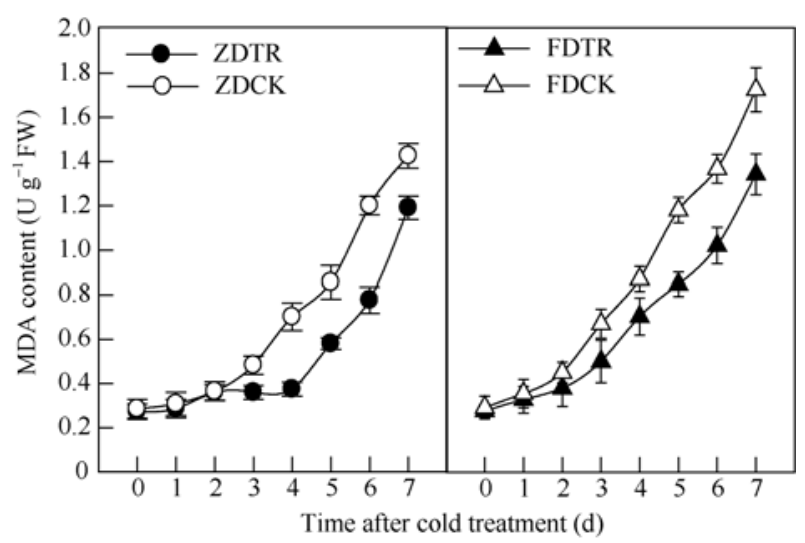

图 5 低温胁迫下聚糠萗合剂对玉米幼苗叶片 MDA 含量的影响

Fig. 5 Effect of PKN on MDA content of maize seedlings under cold stress

ZDTR：郑单 958 处理; ZDCK：郑单 958 对照; FDTR: 丰单 3 号 处理; FDCK: 丰单 3 号对照。

ZDTR: Zhengdan 958 treatment; ZDCK: Zhengdan 958 CK; FDTR: Fengdan 3 treatment; FDCK: Fengdan 3 CK.
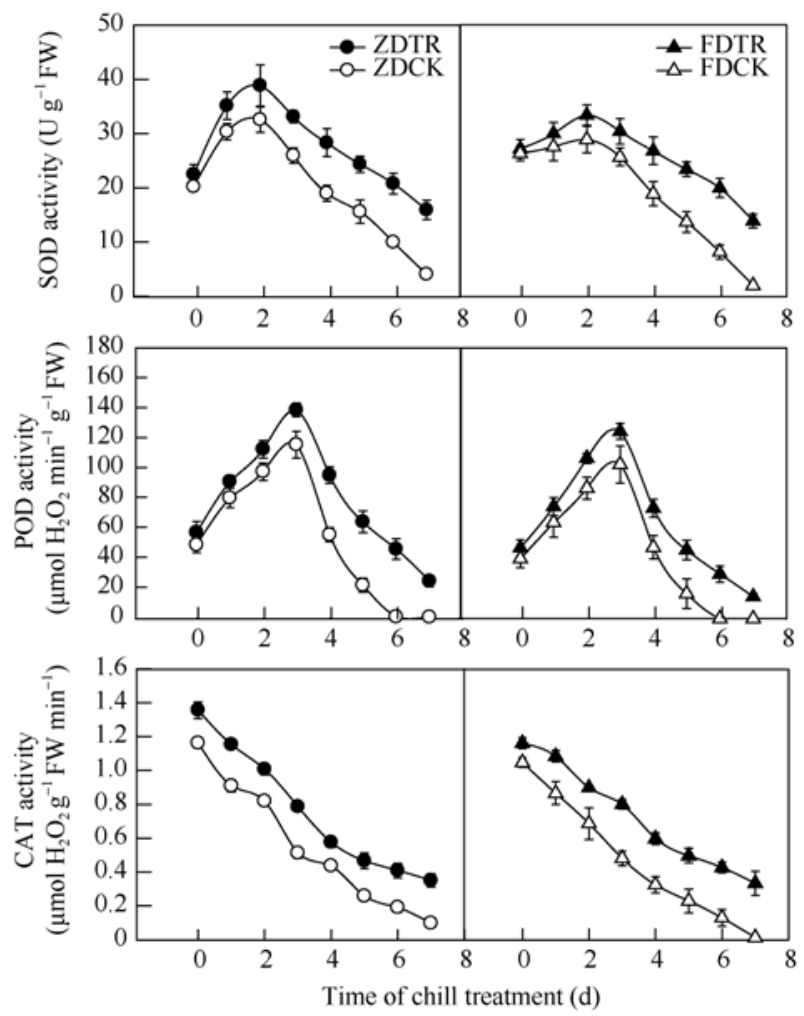

图 6 低温胁迫下聚糠萗合剂对玉米幼苗叶片 SOD、POD、CAT 活性的影响

Fig. 6 Effect of PKN on SOD, POD, CAT activities of maize seedlings under cold stress

ZDTR: 郑单 958 处理; ZDCK：郑单 958 对照; FDTR: 丰单 3 号 处理; FDCK: 丰单 3 号对照。

ZDTR: Zhengdan 958 treatment; ZDCK: Zhengdan 958 CK; FDTR: Fengdan 3 treatment; FDCK: Fengdan $3 \mathrm{CK}$.

POD 是清除过氧化物的酶。与 SOD 酶活性相 似, 不同品种间 POD 活性变化趋势呈单峰曲线, 峰 值出现在低温胁迫 $3 \mathrm{~d}$ 。低温胁迫 $0 \sim 3 \mathrm{~d}$, POD 的活 
性逐渐升高, 与低温处理前相比较, ZDCK 和 FDCK 的 POD 活性分别升高了 $58.04 \%$ 和 $61.17 \%$ 。低温胁 迫 3 7 d, POD 活性急剧下降。其中, 低温胁迫 $7 \mathrm{~d}$, ZDCK 和 FDCK 的 POD 活性比低温处理 $3 \mathrm{~d}$ 分别降 低了 $99.91 \%$ 和 $99.93 \%$ 。PKN 处理显著提高了两品种 POD 活性。低温胁迫 0 7 d, ZDTR 和 FDTR 比各自对 照分别增加了 $12.02 \%$ 295.07\%和 $12.20 \%$ 360.54\%。

CAT 是植物体内清除 $\mathrm{H}_{2} \mathrm{O}_{2}$ 的关键酶之一。随低 温胁迫时间的延长, 两品种的 CAT 活性呈现下降的 趋势。低温处理 $7 \mathrm{~d}$, ZDCK 和 FDCK 的 CAT 活性比 低温处理前分别降低 $91.48 \%$ 和 $99.01 \%$ 。PKN 处理 提高了两品种叶片 CAT 的活性, 低温胁迫 $0 \sim 7 \mathrm{~d}$, ZDTR 和 FDTR 的 CAT 活性比各自对照的增加幅度 分别为 $16.71 \% \sim 254.55 \%$ 和 $10.95 \% \sim 265.45 \%$ 。

\section{3 讨论}

3.1 低温胁迫对玉米幼苗光合性能的影响与化 学调控

光合作用是作物干物质积累和产量形成的基础, 而光合作用最易受低温胁迫的影响 ${ }^{[4]}$ 。李月梅等 ${ }^{[22]}$ 研究表明, 低温降低玉米植株的光合强度和呼吸强 度。低温持续时间越长, 玉米植株光合、呼吸强度 下降的幅度就越大, 发生低温冷害的机率也就越 高。影响最大的时期为二展叶期, 其次为四叶期, 再 次为灌浆期。低温胁迫导致幼苗胞间 $\mathrm{CO}_{2}$ 浓度 $\left(C_{\mathrm{i}}\right)$ 和气孔导度 $\left(G_{\mathrm{s}}\right)$ 下降, 造成光合作用原料 $\left(\mathrm{CO}_{2}\right)$ 供给 不足, 产物运输受阻, 净光合速率 $\left(P_{\mathrm{n}}\right)$ 降低, 同化物 积累量下降, 植株生长势减弱、干物质积累量减少 ${ }^{[23]}$ 。 Allen 等 ${ }^{[24]}$ 研究表明, 低温胁迫下玉米叶片净光合 速率 $\left(P_{\mathrm{n}}\right)$ 和气孔导度 $\left(G_{\mathrm{s}}\right)$ 下降, 而胞间 $\mathrm{CO}_{2}$ 浓度 $\left(C_{\mathrm{i}}\right)$ 上升, 吴雪霞等 ${ }^{[25]}$ 以茄子为试材研究表明, 随低温 胁迫时间的延长胞间 $\mathrm{CO}_{2}$ 浓度 $\left(C_{\mathrm{i}}\right)$ 呈现先降低后升 高的趋势。

本研究结果发现, 低温下玉米幼苗净光合速率 $\left(P_{\mathrm{n}}\right)$ 和气孔导度 $\left(G_{\mathrm{s}}\right)$ 随胁迫时间的延长而下降, 而胞 间 $\mathrm{CO}_{2}$ 的浓度 $\left(C_{\mathrm{i}}\right)$ 随胁迫时间的延长呈先下降后上 升的“ $V$ 型”变化趋势, 并且于胁迫后 $2 \mathrm{~d}$ 达到最低 值。这与吴雪霞等 ${ }^{[25]}$ 的研究结果一致。我们认为, 该 现象可能与低温胁迫程度有关, 轻度低温胁迫导致 光合速率降低的原因是气孔限制, 重度胁迫导致净 光合速率降低原因为非气孔因素限制。即低温胁迫 $2 \mathrm{~d}$ 后, 两品种气孔导度 $\left(G_{\mathrm{s}}\right)$ 均下降, 胞间 $\mathrm{CO}_{2}$ 浓度 $\left(C_{i}\right)$ 降低, 光合速率下降, 这说明该时期净光合速率 降低的主要原因为气孔的限制; 但随着胁迫时间的
延长, $C_{\mathrm{i}}$ 开始上升，而光合速率继续下降，表明该时 期净光合速率降低的主要原因不再是气孔的限制, 可能是其他原因造成的, 如叶绿体结构破损、光合 作用相关酶活性降低, $\mathrm{CO}_{2}$ 同化速率降低，导致了胞 间 $\mathrm{CO}_{2}$ 浓度升高。

PKN 处理延缓了低温胁迫下净光合速率的下降 速率。我们认为原因可能是, 短期度胁迫(低温胁迫 $2 \mathrm{~d}$ )下, PKN 通过减缓叶片气孔导度的下降幅度来提 高运输光合原料和产物的能力, 最终减缓低温胁迫 下玉米的净光合速率下降幅度; 重度胁迫下, PKN 中的主成分细胞分裂素可以促进细胞分裂，延缓衰 老和诱导分化, 并能显著促进叶增大; 同时还能增 强叶片光合作用, 增加叶片叶绿素的含量; 普遍认 为施用外源细胞分裂素能阻止核酸酶、蛋白酶等一 些水解酶的合成或降解这些酶的活性，使核酸、蛋 白质等活性不受破坏或破坏速率减缓。同时细胞分 裂素也增强光合作用 ${ }^{[26]}$, 也可能通过提高与光合作 用相关酶 (RuBP 羧化酶和 PEP 羧化酶)的活性, 减缓 了超氧阴离子的产生速率, 减轻了超氧阴离子对细 胞膜系统和光合系统的破坏, 使细胞膜系统的稳定 性增强, 最终提高了叶片的净光合速率。

3.2 低温胁迫对玉米幼苗叶绿素及叶绿素苂光 参数的影响与化学调控

叶绿素是绿色植物捕获和转化光能的重要物质, 其含量直接影响着光合作用的效率。王连敏等 ${ }^{[27]}$ 研 究表明, 低温胁迫可减少玉米叶片叶绿素含量, 温 度越低叶绿素含量下降得越明显。本研究表明, 低 温胁迫使玉米叶片叶绿素含量降低, 与王连敏等 ${ }^{[27]}$ 研究结果一致。进一步分析发现, PKN 处理在一定 程度上减缓了玉米叶片叶绿素的下降幅度，这可能 与激动素 $(\mathrm{KT})$ 细胞分裂素物质可促进植物叶片中的 叶绿素前体 $\delta$-氨基乙酰丙酸的合成，降低叶绿素酶 mRNA 的含量和叶绿素酶的合成有关 ${ }^{[28]}$, 也可能与 细胞分裂素增强对 $\mathrm{H}_{2} \mathrm{O}_{2}$, 活性氧的清除作用, 维持 玉米叶绿体膜系统的稳定性, 减缓叶绿素的降解速 率有关。PSII 光化学效率 $\left(F_{\mathrm{v}} / F_{\mathrm{m}}\right)$ 是环境胁迫的指标 ${ }^{[29]}$, 在非环境胁迫条件下变化极少。Mauro 等 ${ }^{[30]}$ 以玉米 为材研究表明, 低温影响反应中心和 PS II 电子传递 天线活性, 导致 PSII 光化学抑制, 是由于反应中心 的光损伤和反应中心对激发能捕获能力的降低。 Powells 等 ${ }^{[31]}$ 认为低温下, 植物猝灭激发能力下降, 即使是较低的光强, 也会造成能量过剩, 过剩激发 能一方面影响光能传递, 同时也引起过氧化从而损 伤 PS II 的活性。本研究表明, 低温胁迫导致玉米幼 
苗叶片 $F_{\mathrm{v}} / F_{\mathrm{m}}$ 显著降低, 这可能与低温胁迫致使 PSII 反应中心捕获激发能效率下降, 导致玉米幼苗叶片 PS II 反应中心光化学效率降低有关 ${ }^{[32]}$ 。PKN 处理后 植株 $F_{\mathrm{v}} / F_{\mathrm{m}}$ 的下降趋势明显减缓, 这可能与 PKN 主 成分细胞分裂素可以提高 PSII 的电子传递能力和 天线色素的效率，降低光能耗散，增强了 PSII 反应 中心的光化学效率, 缓解低温对光系统 II 的破坏有 关 ${ }^{[33]}$ 。

3.3 低温胁迫对玉米幼苗抗氧化酶系的影响与 化学调控

超氧化物歧化酶(SOD)、过氧化物酶(POD)和过 氧化氢酶 $(C A T)$ 是作物内在的保护酶系统, 它们既 有分工又有合作, 在作物抗逆代谢中起着重要的保 护作用 ${ }^{[34]}$ 。张敬贤等 ${ }^{[35]}$ 研究表明, 低温处理后, 过 氧化氢酶、过氧化物酶、超氧化物歧化酶活性在玉 米抗冷性差的品种中降低, 在抗冷性强的品种中增 高。熊冬金等 ${ }^{[36]}$ 研究进一步证实了这一现象。本试 验结果表明, 轻度胁迫 (低温胁迫 2 3 d) 使玉米幼苗 SOD、POD 活性上升, 而 CAT 的活性呈下降的趋势, 重度胁迫 (低温胁迫 $7 \mathrm{~d}$ ), 玉米幼苗 SOD、POD, CAT 的活性呈显著下降的趋势。Back 等 ${ }^{[37]}$ 研究表明, 短 期的低温锻炼会使植物体内 SOD、POD 等酶活性升 高, 有利于植株在经受更低温度或更长时间的低温 胁迫时维持较高的抗寒力。据此可以推断前期的 2 3 $\mathrm{d}$ 低温胁迫, 对玉米幼苗而言是抗寒锻炼的过程, 轻 度胁迫可以诱导一些基因的表达，使 SOD、POD 的 活性升高, 一定程度上提高玉米幼苗的抗寒能力。 随着胁迫程度的增强, 破坏了活性氧产生和清除的 平衡关系, 细胞膜系统破坏, 细胞的稳定性降低, 导致玉米幼苗 SOD、POD, CAT 活性显著降低。

PKN 处理提高玉米幼苗体内 SOD、POD、CAT 活性从而降低超氧阴离子 $\left(\mathrm{O}_{2}^{-}\right)$和 $\mathrm{H}_{2} \mathrm{O}_{2}$ 的产生速率, 对细胞膜起到保护作用。但是 CAT 酶对低温胁迫的 反应与 POD、SOD 不同, 这可能由于 CAT 对低温胁 迫比较敏感。PKN 处理植株的 SOD、POD 和 CAT 活性显著高于对照, 可能是由于 PKN 主成分细胞分 裂素刺激了 POD 和 CAT 的产生 ${ }^{[38]}$, 也可能细胞分 裂素维持保护酶活性和小分子清除剂含量, 使植物 体内 $\mathrm{H}_{2} \mathrm{O}_{2} 、 \mathrm{O}_{2}^{-} 、 \cdot \mathrm{OH}$ 等含量一直维持在较低水平, 以 此保护各类功能生物大分子, 减少伤害, 延迟衰老 ${ }^{[39]}$ 。 随着低温胁迫的加重, 细胞膜系统的完整性受到严 重破坏, 电解质渗透增加, 有害物质含量增加, 导 致酶的产生受阻, PKN 处理提高的 CAT 和 POD 活性 与低温胁迫降低酶活性的速率失衡, 导致冻害发生。

\section{4 结论}

低温胁迫，玉米幼苗的光合作用抑制， $F_{\mathrm{v}} / F_{\mathrm{m}}$ 降 低, 叶绿素含量下降。同时过氧化氢、超氧阴离子 的产生速率及丙二醛(MDA)的含量显著升高。抗氧 化酶系统中的超氧化物歧化酶(SOD)、过氧化物酶 (POD)和过氧化氢酶(CAT)活性降低。PKN 处理能显 著缓解低温胁迫对净光合速率 $\left(P_{\mathrm{n}}\right) 、$ 气孔导度 $\left(G_{\mathrm{s}}\right)$ 、 光系统 II 光化学的最大效率 $\left(F_{\mathrm{v}} / F_{\mathrm{m}}\right)$ 、叶绿素含量的 影响; 降低过氧化氢、超氧阴离子的产生速率及 MDA 的含量; 提高 SOD、POD、CAT 活性。从而 提高玉米幼苗的抗寒性。

\section{References}

[1] Meng Y(孟英), Li M(李明), Wang L-M(王连敏), Wang L-Z(王 立志), Feng Y-J(冯延江). Effects of chilling injury on maize and correlative research. Heilongjiang Agric Sci (黑龙江农业科学), 2009, (4): 150-153 (in Chinese with English abstract)

[2] Ma Q-S(马树庆), Xi Z-X(袭祝香), Wang Q(王琪). Risk evaluation of cold damage to corn in northeast China. $J$ Nat Disasters (自然灾害学报), 2003, 12(3):137-141 (in Chinese with English abstract)

[3] Guan X-J(关贤交)，Ou-Yang X-R(欧阳西荣). The research of low temperature on maize. Crop Res (作物研究), 2004, (1): 16 (in Chinese with English abstract)

[4] He J(何洁), Liu H-X(刘鸿先), Wang Y-R(王以柔), Guo J-Y(郭 俊彦). Low temperature and photosynthesis of plants. Plant Physiol Commun (植物生理学通讯), 1986, 22(2): 1-6 (in Chinese with English abstract)

[5] Shi Z-Z(史占忠), Ben X-M(贲显明), Zhang J-T(张敬涛). The emerging pattern and preventive measure of maize cold damage in the sanjiang river plain. Heilongjiang Agric Sci (黑龙江农业 科学), 2003, (2): 7-10 (in Chinese with English abstract)

[6] Fryer M J, Andrews J R, Oxborough K. Relationship between $\mathrm{CO}_{2}$ assimilation, photosynthetic electron transport, and active $\mathrm{O}_{2}$ metabolism in leaves of maize in the field during periods of low temperature. Plant Physiol, 1998, 116: 571-580

[7] Gao M-Z(高妙真). Mechanism of chilling injury of corn and the effect of chemical control to prevent chilling. J Northeast Agric Univ (东北农业大学学报)，1989，20(4)：295-299 (in Chinese with English abstract)

[8] Kraus T E, Fletcher R A. Paclobutrazol protects wheat seedlings from heat and paraquat injury. Is detoxification of active oxygen involved? Plant Cell Physiol, 1994, 35: 45-52

[9] Beaucorps G D, Leymomnie J P. Potassium and Crop Health (钾 与作物(健康). Nanjing: Phoenix Science Press, 1989. pp 29-37

[10] Zhang F-S(张福锁). Environment Stress and Plant Nutrition (环 境胁迫与植物营养). Beijing: China Agricultural University Press, 1993. pp 148-170

[11］Zou G-Y(邹国元), Yang Z-F(杨志福), Li X-L(李晓林). Effect of potassium on chilling resistance of maize seedling. Plant Nutr Fert Sci (植物营养与肥料学报), 1998, 4(2)：165-169 (in Chinese with English abstract) 
[12] Liu Y(刘芸), Zhong Z-C(钟章成), Marinus J A, Cao G-X(操国 兴), Yin K-L(尹克林), Long Y(龙云). Effects of $\alpha$-NAA and UV-B radiation on photosynthetic pigments and activities of protective enzymes in Trichosanthes kirilowii Maxim leaves. Acta Ecol Sin (生态学报), 2003, 23(1): 12-15 (in Chinese with English abstract)

[13] Leshem Y Y, Wurzburger J, Grossman S. Cytokinin interaction with tree radical metabolism and senescence. Physiol Plants, 1981, 53: 9-12

[14] Leng Y-X(冷一欣), Rui X-S(芮新生), He P-H(何佩华). Study of the yield increasing of maize by using polyaspartic acid. $J$ Maize Sci (玉米科学), 2005, 13(3): 100-102 (in Chinese with English abstract)

[15] Arnon D I, Whatley F R. Factors influencing oxygen production by illuminated chloroplast fragments. Archiv Biochem, 1949, 23: 141-156

[16] Lin Z-F(林植芳), Li S-S(李双顺), Lin G-Z(林桂珠), Guo J-Y(郭 俊彦). The accumulation of hydrogen peroxide in senescing leaves and chloroplasts in relation to lipid peroxidation. Acta Photophysiol Sin (植物生理学报), 1988, 14(1): 16-22 (in Chinese with English abstract)

[17] Wang R-G(王爱国), Luo G-H(罗广华). Quantitative relation between the reaction of hydroxylamine and superoxide anion radicals in plants. Plant Physiology Commun (植物生理学通讯), 1990, (6): 55-57 (in Chinese with English abstract)

[18] Chance B, Maehly A C. Assay of catalase and peroxidase. Methods Enzymol, 1955, 12: 764-775

[19] Li Z-G(李忠光), Li J-H(李江鸿), Du C-K(杜朝昆). Simultaneous measurement of five antioxidant enzyme activities using a single extraction system. J Yunnan Normal Univ (Nat Sci Edn) (云南师范大学学报·自然科学版), 2002, 22(6): 44-48 (in Chinese with English abstract)

[20] Lin Z-F(林植芳), Li S-S(李双顺), Lin G-Z(林桂珠), Sun G-C(孙 谷畴), Guo J-Y(郭俊彦). Superoxide dismutase activity and lipid peroxidation in relation to senescence of rice leaves. Acta Bot Sin (植物学报), 1984, 26(6): 605-615 (in Chinese with English abstract)

[21] Demming-Adams B. Carotenoids and photoprotection in plants: a role of Xanthophyll zeaxanthin. Biochim Biophys Acta, 1987, 1020: $1-24$

[22] Li Y-M(李月梅), Ma Y-Y(马荣䒯), Yang Y-L(杨英良), Meng $\mathrm{L}$ (孟良). The effect of low temperature on photosynthesis and respiration. Heilongjiang Agric Sci (黑龙江农业科学), 1991, (6): 4-8 (in Chinese)

[23] Fan H-F(樊怀福), Jiang W-J(蒋卫杰), Guo S-R(郭世荣). Effects of low temperature on growth and photosynthesis of tomato seedlings. Jiangsu Agric Sci (江苏农业科学), 2005, (3): 89-91 (in Chinese with English abstract)

[24] Allen D J, Ort D R. Impacts of chilling temperatures on photosynthesis in warm climate plant. Trends Plant Sci, 2001, 6: 36-41

[25] Wu X-X(吴雪霞), Chen J-L(陈建林), Zha D-S(查丁石). Effects of low temperature stress on photosynthetic characteristics in leaves of egg plant seedlings. Acta Agric Boreali-Sin (华北农学 报), 2008, 23(5): 185-189 (in Chinese with English abstract)

[26] Meng F-J(孟繁静), Liu D-H(刘道宏), Su Y-Y(苏业瑜). Plant Physiology and Biochemical (植物生理生化). Beijing: China
Agriculture Press, 1995. pp 11-16 (in Chinese)

[27] Wang L-M(王连敏), Wang L-Z(王立志). Effect of low temperature at seedling stage on proline, electric conductivity and photosynthesis. Chin J Agrometeorol (中国农业气象), 1999, 20(2): 28-31 (in Chinese with English abstract)

[28] Jiang L(江力), Kong X-W(孔小卫), Zhang R-X(张荣铣). Effects of 6-benzyladenine and abscisic acid on the photosynthetic function decline in tobacco. J Nanjing Agric Univ (南京农业大学学 报), 2006, 29(4): 127-130 (in Chinese with English abstract)

[29] Chen J-M(陈建明), Yu X-P(俞晓平), Cheng J-A(程家安). The application of chlorophyll fluorescence kinetics in the study of physiological responses of plants to environmental stresses. Acta Agric Zhejiangensis (浙江农业学报), 2006，18(1)：51-55 (in Chinese with English abstract)

[30] Mauro S, Dainsese P, Lannoye R, Bassi R. Cold resistant and cold susceptible maize lines differ in the phosphorylation of the photo system II subunit. Plant Physiol, 1997, 115: 171-177

[31] Powles S B, Berry J A, Björkman O. Interaction between light and temperature on the inhibition of photosynthesis in chillingsensitive plants. Plant Cell Environ, 1983, 6: 117-123

[32] Carrasco R M, Rodriguez J S, Perez P. Changes in chlorophyll fluorescence during the course of photoperiod and in response to drought in Casuarina equisetifolia Forst. Photosynthetica, 2002, 40: $363-368$

[33] Liu Q-D(刘清岱), Zhu Y-R(朱晔荣), Tao H-L(陶汉林), Wang Y(王勇). The change of PSII of Spirod elapolyrrhiz a half-2fronds and the effect of cytokinin. In: Abstracts of Research Papers Presented at the 9th National Meeting of the Chinese Society for Plant Physiology. Shanghai: Biophysical Chemistry, 2004

[34] Zhang R(张莈), Lü J(吕俊), Mi Q-S(米青山), Wang S-Y(王三 根). Effects of salicylic acid on the antioxidant enzymes of rice seedlings during chilling stress. J Southwest Agric Univ (Nat Sci) (西南农业大学学报·自然科学版), 2006, 28(1): 29-36 (in Chinese with English abstract)

[35] Zhang J-X(张敬贤), Li J-M(李俊明), Zhang H-M(张海明). The effect of low temperature on activities of cell protective enzymes and protoplasmic parameters in leaves of Zea mays. Acta Agric Boreali-Sin (华北农学报), 1993，8(3)：9-12 (in Chinese with English abstract)

[36] Xiong D-J(熊冬金), Lin Z-H(林志红), Chang B-Y(畅柏云), Zhu B-F(朱必凤), Zhu Y-L(朱友林). Studies of four kind of isozymes and the changes of content of mailond laldehyde in maiiein waterlogging or chilling stress. J Nanchang Univ (南昌大学学报), 1996, 20(4): 314-319 (in Chinese with English abstract)

[37] Back K H, Skinner D Z. Alteration of antioxidant enzyme gene expression during cold ac climation of near-isogonics wheat lines. Plant Sci, 2003, 165: 1221-1227

[38] Liao X-R(廖祥儒), He P-C(贺普超), Zhu X-C(朱新产). Effect of zeatbsf in $\mathrm{H}_{2} \mathrm{O}_{2}$ scavenging system of Vitis vulpina leaf disks under salt stress. Acta Bot Sin (植物学报), 1997, 39(7): 641-646 (in Chinese with English abstract)

[39] Yin K-D(殷奎德), Hu W-Y(胡文玉). Cytokinin effect on active oxygen during in vitro senescence of wheat leaves. J Heilongjiang Bayi Agric Univ (黑龙江八一农崖大学学报), 1994, 7(4): 16-22 (in Chinese with English abstract) 